\title{
Francité, américanité et indianité dans le roman québécois contemporain, textes réunis et présentés par Victor BERNOVSKY
}

\section{Elena Fermi}

\section{(2) OpenEdition}

Journals

\section{Édition électronique}

URL : http://journals.openedition.org/studifrancesi/16829

DOI : $10.4000 /$ studifrancesi. 16829

ISSN : 2421-5856

Éditeur

Rosenberg \& Sellier

\section{Édition imprimée}

Date de publication : 1 juillet 2019

Pagination : 208-210

ISSN : 0039-2944

\section{Référence électronique}

Elena Fermi, «Francité, américanité et indianité dans le roman québécois contemporain, textes réunis et présentés par Victor Bernovsky », Studi Francesi [En ligne], 187 (LXIII | I) | 2019, mis en ligne le 01 juillet 2019, consulté le 25 janvier 2021. URL : http://journals.openedition.org/studifrancesi/16829 ; DOI : https://doi.org/10.4000/studifrancesi. 16829

Ce document a été généré automatiquement le 25 janvier 2021.

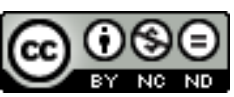

Studi Francesi è distribuita con Licenza Creative Commons Attribuzione - Non commerciale - Non opere derivate 4.0 Internazionale. 


\title{
Francité, américanité et indianité dans le roman québécois contemporain, textes réunis et présentés par Victor BERNOVSKY
}

\author{
Elena Fermi
}

\section{RÉFÉRENCE}

Francité, américanité et indianité dans le roman québécois contemporain, textes réunis et présentés par Victor BERNOVSKY, nov.-déc. 2017, Lecce, Alliance Française, «Interculturel francophonies» $32,326 \mathrm{pp}$.

1 Le présent volume fait partie de la collection de la revue Interculturel francophonies que l'Alliance Française de Lecce publie depuis 2001 et qui a été consacrée, au fil des années, aux littératures francophones extra-européennes. Après s'être occupée des littératures des îles, du Maghreb, du Moyen-Orient, avec ce volume la revue se penche sur la littérature québécoise ou, plus précisément, sur le roman contemporain produit dans cette région francophone du Canada. Une littérature encore peu connue en dehors de son territoire d'origine mais qui, au fur et à mesure de la lecture, se révèle extrêmement dynamique et novatrice. Le volume réunit des articles de divers contributeurs, des universitaires pour la plupart, qui abordent les problématiques de la francité, de l'américanité et de l'indianité dans le roman contemporain. Le but est celui de relancer le discours sur l'identité québécoise, une identité qui se révèle être plurielle, canadienne, française, amérindienne, à cheval entre un monde minoritairement francophone et majoritairement anglophone et qui, du point de vue plus strictement littéraire, se développe dans un espace où le code littéraire français et la civilisation américaine s'interposent et se superposent. La problématique du 
métissage est abordée par les contributeurs, qui y voient une caractéristique fondamentale de cette production littéraire.

2 Après une introduction où BERNOVSKY présente les lignes générales des articles qui vont suivre, le volume se divise en quatre sections. La première se penche sur la société québécoise et son évolution et comprend deux articles. Patrick IMBERT aborde la problématique de l'identité de la société américaine, en analysant son évolution à partir du XIX ${ }^{e}$ siècle jusqu'aujourd'hui. Suivant son discours si, au départ, le but du colonisateur venant du vieux continent a été celui de construire des sociétés homogènes à dominante européenne, au fil du temps les mémoires autochtones, celles des afro-descendants et des métis de tout genre ont amené cette société vers un multiculturalisme transnational, que l'on observe désormais surtout dans l'espace littéraire et artistique. Jean-François LÉTOURNEAU examine, quant à lui, la notion d'américanité qui interpellerait - dit-il - les écrivains québécois issus d'une culture née du croisement entre la terre américaine et l'histoire française. C'est notamment la notion de «Nouveau Monde» que l'auteur entend remettre en question, en tant qu'idée tirée de l'imaginaire européen et surimposée sur la réalité américaine. En parcourant les essais de René Lapierre, Luc Bureau et Georges Sioui où le concept d'américanité se prolonge dans celui d'américité, il en conclut que l'écriture américaine ne peut désormais se passer de dialoguer avec les cultures de ceux qu'il appelle les Premiers Peuples. Par rapport aux lettres québécoises, l'auteur fait un détour par Kerouac dont l'influence sur les écrivains de ce territoire est connue et documentée, pour ensuite se pencher sur la réhabilitation, à laquelle on assiste - paraît-il - depuis quelques années, du terme sauvage. À travers un corpus de nouvelles et de romans publiés dans les dix dernières années, LÉTOURNEAU relève que la production littéraire récente au Québec s'inspire de plus en plus des réalités des Premiers Peuples, en un renversement de perspective entre barbarie et civilisation. La deuxième partie, consacrée à la Transformation des littératures autochtones comprend les contributions de François PARÉ et de Jeanette DEN TOONDER. Paré tente d'évoquer, en une série d'instantanés, la littérature québécoise du siècle actuel. Conscient du défi que cela représente, il entreprend malgré tout d'en présenter les principaux écrivains, les œuvres marquantes et les institutions. Suivant son raisonnement, on découvre un univers littéraire audacieux, riche de toutes les tensions et les impuissances de notre époque. Son analyse se développe sur quatre grands champs thématiques et institutionnels: le renouvellement du milieu de l'édition littéraire et la reconnaissance des littératures autochtones d'expression française d'un côté, les motifs internes qui structurent le contenu des œuvres comme les représentations de l'intime et la lutte contre les hégémonies de l'autre. Den Toonder se penche, quant à elle, sur l'écriture féminine, en particulier sur celle des femmes autochtones et migrantes, en mettant en avant les voix de Kim Thúy et de Virginia Pésémapéo Bordeleau. Son corpus comprend les deux romans Ourse bleue et $R u$, à travers lesquels l'auteure analyse quelques thèmes principaux de ces écritures: les liens familiaux, les voyages à la recherche des origines perdues, les souvenirs et les rêves qui s'y imbriquent afin de donner une voix aux expériences individuelles de femmes vivant entre deux cultures qu'elles cherchent à fusionner. La troisième section du volume, traitant la problématique de la francité et de l'indianité, comprend elle aussi deux articles, dans lesquels les contributeurs se penchent chacun sur un petit corpus de romans, afin d'en mettre en relief quelques sujets majeurs. C'est notamment la problématique du métissage qui est mise en avant par Nicolas DAVIGNON, grâce à 
l'analyse de Petit Homme Tornade de Roch Carrier. Selon le chercheur, la dualité qui existe au Québec depuis l'arrivée de l'homme blanc européen offre au romancier la possibilité de faire s'affronter les deux cultures qui composent le mythe américain: celle du vieux continent et l'amérindienne. Au final, la confrontation se résout dans la prise de conscience d'une identité qui ne peut qu'être le fruit du métissage canadien, français et indien. Sylvie VIGNES choisit comme corpus le roman Ce qu'il reste de moi de Monique Proulx, afin d'analyser le portrait que l'écrivaine fait de la ville de Montréal, ville à laquelle elle réserve la place d'honneur dans ses œuvres fictionnelles. Ce qu'il reste de moi est, suivant le point de vue de l'auteure, un roman polyphonique où plusieurs voix s'entrecroisent et où des épisodes actuels s'alternent avec des épisodes remontant au XVII siècle. En offrant au lecteur les points de vue de personnages aux origines différentes, dont un amérindien et un inuit, VIGNES aborde les problématiques de la francité et de l'indianité comme composantes principales de l'identité québécoise, une identité qui reste toutefois très mouvante à cause de l'immigration intensifiée pendant les dernières années. La quatrième section Francité et/ou américanité, avec ses dix articles est la plus développée. Adrien GUYOT retrace l'histoire du développement au Québec de l'imaginaire américain, un imaginaire qui connaît des moments de grande force et des moments de crise et qui est, de toute manière, toujours imprégné d'une certaine ambivalence vis-à-vis des États-Unis, perçus comme très proches mais, en même temps, très dangereux du point de vue de leur «colonisation» culturelle. Guyot met en relief comment, au fil des décennies et surtout à partir des années soixante, l'américanité devient un chiffre commun de la production littéraire québécoise jusqu'à ce qu'il émerge, dans les années 1990, un cadre littéraire digne de ce nom. Si la place des États-Unis est d'abord prépondérante, elle s'efface peu à peu à partir des années 2000 au profit d'une reconnaissance de l'hétérogénéité des cultures en présence dans les Amériques. La québécitude laisserait donc la place, suivant l'auteur, à une redéfinition identitaire qui passe par le métissage biologique et culturel que l'appartenance au continent américain impose. Jean MORENCY pose la question de la dimension multiple de l'identité québécoise à travers l'analyse du roman de Jacques Poulin Les yeux bleus de Mistassini. Ce que le chercheur veut souligner en analysant les personnages et l'histoire du roman est surtout la cohabitation, dans cette identité, de l'américanité et de la francité, d'une culture franco-américaine, entendue dans son sens anthropologique. Le problème de l'influence très puissante des États-Unis et, plus en général, de l'univers anglophone sur le Québec et sa littérature est abordé par Madeleine MONETTE, romancière originaire de Montréal mais qui a choisi de vivre à New-York. C'est donc en migrante qu'elle traite le sujet, en en observant l'évolution au fil des années. Selon elle si, au départ, la littérature québécoise a été perçue comme basée sur la survivance, devant protéger et défendre des racines et des traditions, son évolution l'a amenée vers une ouverture au monde et à l'Autre qui l'a faite se réinventer dans une diversité complexe. La franco-américanité québécoise fait également l'objet de l'article de Jimmy thiBEAULt, qui traite cette problématique en analysant L'année la plus longue de Daniel Grenier. Après l'examen de quelques notions associées aux enjeux identitaires, l'auteur se penche sur l'histoire du roman, le récit de deux vies qui se succèdent, celle d'Aimé Bolduc et celle de son grand-fils Thomas, qui deviennent des symboles à la fois de la présence française en Amérique et de l'appartenance culturelle au continent nord-américain. Jacques Poulin revient à l'honneur dans l'article de Victor BERNOVSKY concernant les héros de ses romans, des romans de la route comme il les définit dès le début. L'auteur s'attache à Volkswagen 
Blues, en relevant les composantes identitaires dont la quête caractérise les héros, qu'il rapproche de quelques romans de la route du monde anglophone, sans oublier, bien évidemment, un détour par Kerouac, dont le roman-témoignage On the Road a servi d'exemple à tous les écrivains successifs. Ce sont des romans de la route, des récits de voyage, à la découverte d'un espace et à la recherche de soi. Voichita-Maria SASU analyse les manifestations de l'américanité dans La Pêche blanche de Lise Tremblay où le territoire nord-américain tient la vedette, tant du point de vue physique que du point de vue psychique, puisque l'idée de la romancière est que le territoire et le climat influencent les caractères. Le roman développe une série de relations binaires: nord/ sud, chaud/froid, bruit/silence, dynamisme/immobilité à travers l'histoire de deux frères qui ont fait des choix de vie différents mais qui, malgré leurs distances, partagent le même esprit. Élisabeth NARDOUT-LAFARGE s'intéresse à la thématisation du conflit des langues dans Folle de Nelly Arcan et Fleurs de crachat de Catherine Mavrikakis. Suivant l'analyse de la chercheuse ces deux romans remettraient à l'honneur la singularité et la supériorité françaises qui tendent, en revanche, à disparaître dans l'imaginaire social contemporain du Québec et ils le feraient à travers un discours linguistique. Si Folle raconte un conflit entre langues majoritaire et minoritaire demeuré actif et souffrant, Fleurs de crachat rend compte d'un conflit qui ne peut plus avoir lieu, la domination de la norme française s'y trouvant réduite à un enjeu révolu. Malgré leurs différences cependant, les deux textes attachent à la parole française des traits de maîtrise, de force, de domination, de puissance séductrice qui remettent au centre du discours la francité québécoise. La reprise américano-québécoise du mythe d'Icare est à l'honneur dans l'article d'Eva VOLDǨICHOVÁ BERÁNKOVÁ qui aborde le thème du roman, du mythe, de l'épopée à l'époque du numérique à travers l'analyse de la trilogie d'Éric Plamondon 1984. La montée vers les étoiles et la chute brutale qui s'ensuit - comme pour Icare caractérisent la vie et le destin des héros de la trilogie qui poursuivent le rêve américain sans se rendre compte du fait que ce rêve est éphémère et expose à des conséquences qui peuvent être tragiques. Quatre récits de voyage de Louis Gauthier sont pris en compte par Frédéric RONDEAU qui s'attache à l'héritage de la contre-culture. Le voyage vers l'Inde qu'entreprend le protagoniste représente une quête identitaire. La destination du périple reste cependant inatteignable d'où une cuisante déception qui conduit le narrateur à cesser d'écrire et, en même temps, à faire retour à son Québec natal où il comprend qu'au bout du compte il y a ses vraies racines. Le phénomène du déplacement des jeunes québécois vers les provinces de l'Ouest canadien est un sujet majeur de quelques romans contemporains. Jérôme MELANçon fait le choix de l'aborder dans son article, en analysant un corpus de quatre ouvrages: Go West Gloria de Sarah Rocheville, Edmonton de Guillaume Bernwald, Okanagan de Sara Lazzaroni et Le mur mitoyen de Catherine Leroux. L'auteur définit ces romans des «romans du séjour» qui se situeraient donc, selon lui, dans un continuum entre les romans de la route et les romans de l'Ouest canadien. Leurs protagonistes se caractérisent en effet pour le fait qu'ils vont vers les provinces anglophones occidentales justement pour un «séjour» avec l'idée de retourner un jour ou l'autre dans leur province d'origine. La problématique mise en avant est celle de l'adaptation des jeunes héros au milieu anglophone, adaptation qui va de soi grâce à la connaissance de l'anglais que les personnages ont en commun, sauf dans le cas de Gloria, la protagoniste du roman de Sarah Rocheville qui se retrouve même à l'Ouest en milieu francophone. Elle est partie pour délaisser une part d'elle-même, ce qui impliquerait d'abandonner aussi sa langue maternelle et elle a l'impression de vivre un drame, en entendant parler français 
autour d'elle. Le séjour est un arrêt qui sert à se réinventer, se transformer en acquérant de nouveaux points de repères. L'Ouest lointain mais familier, devient un endroit mythique qui permet cette renaissance. Chaque contribution est suivie de la bibliographie de référence et en annexe on trouve une bio-bibliographie sommaire des collaborateurs.

3 La lecture du volume permet de découvrir des éléments d'une littérature encore peu connue, qui se révèle être digne d'intérêt et d'approfondissement. 